\section{Thank you and goodbye!}

\author{
Tore K Kvien
}

I am grateful for the opportunity to be Editor in Chief for Annals of the Rheumatic Diseases (ARD) since 1st of April 2008. I was fortunate to succeed Professor Leo van de Putte who had been the successful Editor of this European League Against Rheumatism (EULAR) journal since 1999. ${ }^{1}$ Importantly, he was my teacher when I started. ${ }^{2}$ Editorial responsibility for a leading scientific journal means that you need to cover a broad area, that is, research work from 'bench to bedside'. My first step was actually to identify weaknesses in my own knowledge and invite experts in these areas as associate editors or editorial board members to fill these gaps of knowledge. These colleagues have all been extremely important for the increasing success of $A R D$ during the recent years.

What has then been achieved? First, the impact factor (IF) has been increasing and reached the highest number ever in rheumatology this year (IF 2016 for ARD announced in June 2017 was 12.811). Most rheumatologists have during the recent years considered $A R D$ as the world leading journal in rheumatology. We have seen an increasing number of submissions-but the annual number has been stable around 2000 during the most recent years. The acceptance rate for original research articles is now around 12\% and the instant reject rate about $70 \%$. Editorial decisions for instantly rejected papers occur in average after 7 days and after 43 days for papers which have been to external review. I feel confident that the quality of published papers has improved-and I am very satisfied to see that the journal publishes a good mixture of high quality science not only in clinical and epidemiological research, but increasingly also in basic and translational science. Most importantly, I think ARD is also presenting results from research that will lead to better patient care when new

Correspondence to Professor Tore K Kvien,

Department of Rheumatology, Diakonhjemmet Hospital, Vindern, N-0319 Oslo, Norway;

t.k.kvien@medisin.uio.no

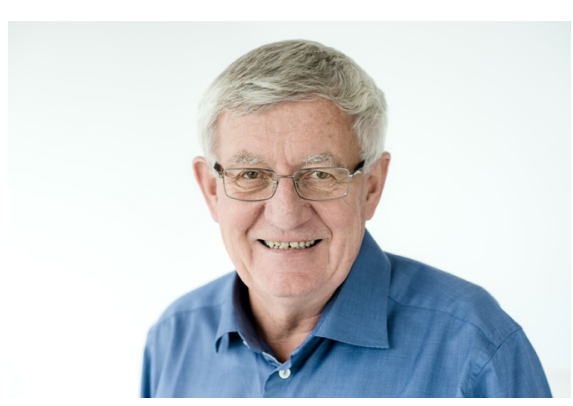

findings are implemented into clinical practice. The development of lay summaries of selected articles (usually three per issue) has also supported dissemination of research findings that can enhance patient care.

The editorial process is a team work and I am very grateful for the important contributions from many people. The associate editors and the editorial board members have been essential both as advisors, second opinion assessors and reviewers. I am also in particular grateful for the work performed by the editorial assistant, Christine Janssen-Seijkens, based on her knowledge, experience and dedication. The statistical advisor has contributed a lot to the scientific quality of the published papers. $^{3}$ More recently, the journal has also benefited from graphic advises. Another recent new important initiative has been to establish a social media group from Emerging EULAR Network. ${ }^{4}$ I have enjoyed the support, collaboration and friendship with the editorial team of the BMJ Publishing Group as well as the leadership group of EULAR. Finally, the journal could never have achieved its current standard without the support from many colleagues who submit their high quality research papers to $A R D$ - and not least the external reviewers who provide excellent assessments of papers sent out for external review.

I have immensely enjoyed these years as Editor of $A R D$, but it is now time for a replacement. I am very happy about the selection of my good friend and colleague, Professor Josef Smolen (Vienna, Austria),

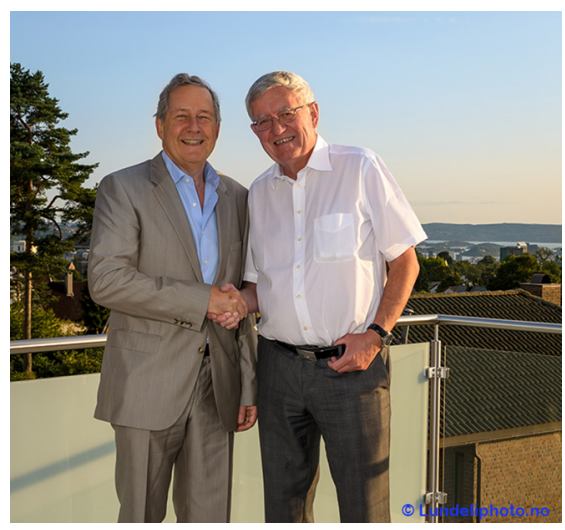

as my successor. He started to handle new submissions as of 1st September (I will continue to handle papers which I have sent out for review until final decisions have been made). I am confident that Josef will maintain and further enhance elements in the editorial process that have been successful, but also that he will bring new and innovative ideas which will further strengthen the quality and standing of the journal. I wish Josef and his editorial team all the best for the coming years!

\section{Competing interests None declared.}

Provenance and peer review Commissioned; internally peer reviewed.

(C) Article author(s) (or their employer(s) unless otherwise stated in the text of the article) 2017. All rights reserved. No commercial use is permitted unless otherwise expressly granted.

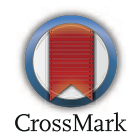

To cite Kvien TK. Ann Rheum Dis 2017;76:1635.

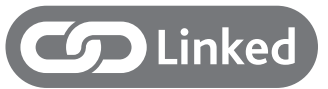

- http://dx.doi.org/10.1136/annrheumdis-2017212236

Ann Rheum Dis 2017;76:1635.

doi:10.1136/annrheumdis-2017-212235

\section{REFERENCES}

1 van de Putte L. Goodbye and thank you. Ann Rheum Dis 2008;67:437.

2 Kvien TK. The new Editor greets you. Ann Rheum Dis 2008;67:437-8.

3 Lydersen S. Statistical review: frequently given comments. Ann Rheum Dis 2015;74:323-5.

4 Nikiphorou E, Studenic P, Ammitzbøll CG, et al. Social media use among young rheumatologists and basic scientists: results of an international survey by the Emerging EULAR Network (EMEUNET). Ann Rheum Dis 2017;76:712-5. 